University of Wollongong

Research Online

Australian Institute for Innovative Materials -

Papers

Australian Institute for Innovative Materials

$1-1-2016$

Superior sodium-ion storage performance of Co304@nitrogen-doped carbon: derived from a metal-organic framework

Ying Wang

Nankai University, University Of Wollongong, yw826@uow.edu.au

Caiyun Wang

University of Wollongong, caiyun@uow.edu.au

Yijing Wang

Nankai University

Hua-Kun Liu

University of Wollongong, hua@uow.edu.au

Zhenguo Huang

University of Wollongong, zhenguo@uow.edu.au

Follow this and additional works at: https://ro.uow.edu.au/aiimpapers

Part of the Engineering Commons, and the Physical Sciences and Mathematics Commons

Research Online is the open access institutional repository for the University of Wollongong. For further information contact the UOW Library: research-pubs@uow.edu.au 


\title{
Superior sodium-ion storage performance of Co304@nitrogen-doped carbon: derived from a metal-organic framework
}

\author{
Abstract \\ Nitrogen-doped carbon coated Co 304 nanoparticles (Co 304 @NC) with high Na-ion storage capacity \\ and unprecedented long-life cycling stability are reported in this paper. The Co 304 @NC was derived \\ from a metal - organic framework ZIF-67, where the Co ions and organic linkers were, respectively, \\ converted to Co 304 nanoparticle cores and nitrogen-doped carbon shells through a controlled two-step \\ annealing process. The Co $304 @ N C$ shows a porous nature with a surface area of $101 \mathrm{~m} 2 \mathrm{~g} 1$. When \\ applied as an anode for sodium ion batteries (SIBs), Co 304 @NC delivers a high reversible capacity of \\ 506,317 , and $263 \mathrm{~mA} \mathrm{~h} \mathrm{~g} 1$ at 100,400 , and $1000 \mathrm{~mA} \mathrm{~g} 1$, respectively. A capacity degradation of $0.03 \%$ \\ per cycle over 1100 cycles was achieved at a high current density of $1000 \mathrm{~mA} \mathrm{~g} 1$. The outstanding Na- \\ ion storage performance can be ascribed to the nitrogen-doped carbon coating (NC), which facilitates the \\ capacitive reaction, minimizes the volume changes of Co 304 , and also enhances the electronic \\ conductivity. This work sheds light on how to develop high-performance metal oxide@NC \\ nanocomposites for SIBs
}

\section{Keywords}

performance, co3o4, nitrogen, doped, carbon, derived, metal, organic, superior, framework, sodium, ion, storage

\section{Disciplines}

Engineering | Physical Sciences and Mathematics

\section{Publication Details}

Wang, Y., Wang, C., Wang, Y., Liu, H. \& Huang, Z. (2016). Superior sodium-ion storage performance of Co304@nitrogen-doped carbon: derived from a metal-organic framework. Journal of Materials Chemistry A, 4 (15), 5428-5435. 


\section{Journal of}

Materials Chemistry A

Materials for energy and sustainability

www.rsc.org/MaterialsA
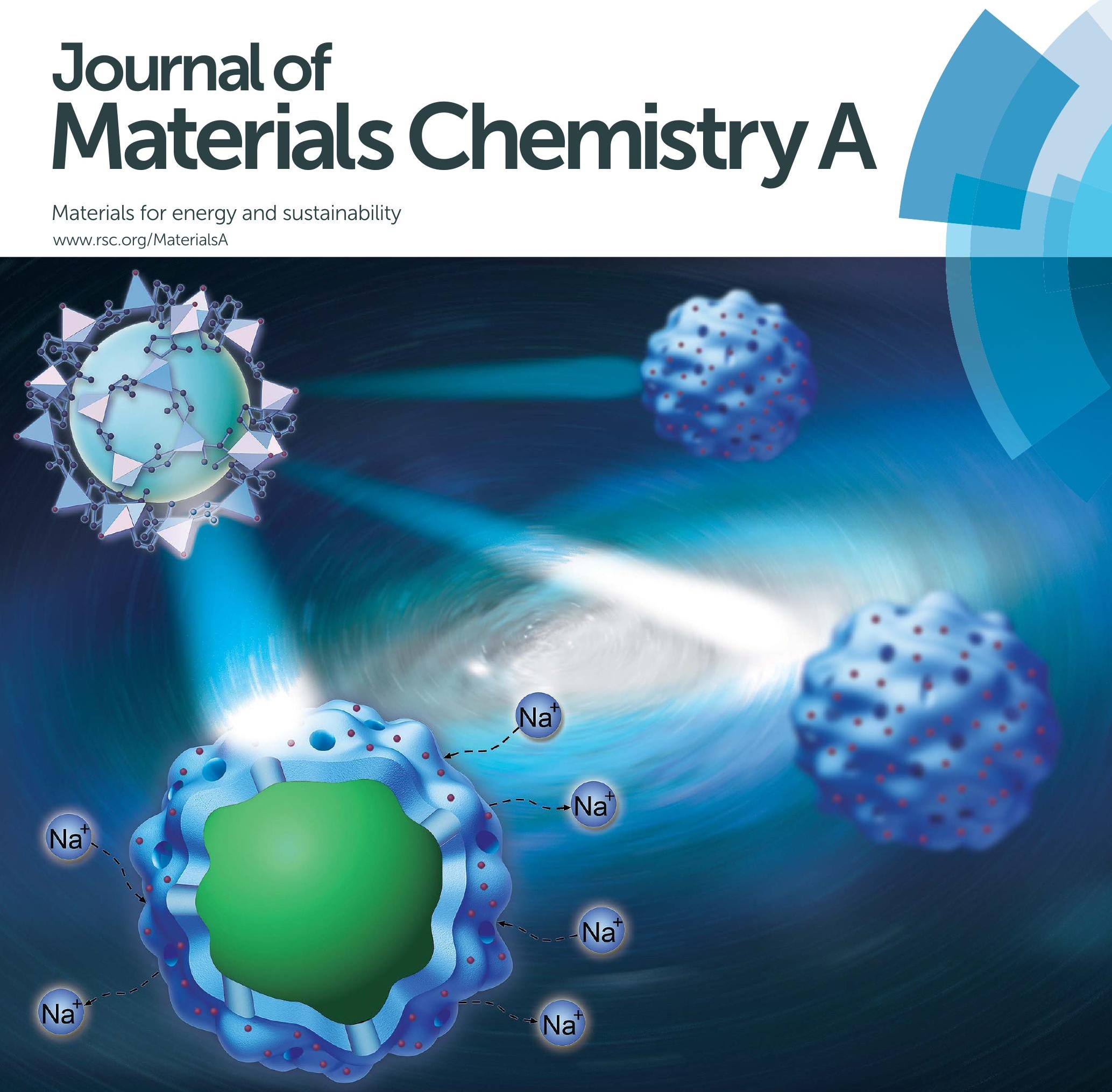

ISSN 2050-7488

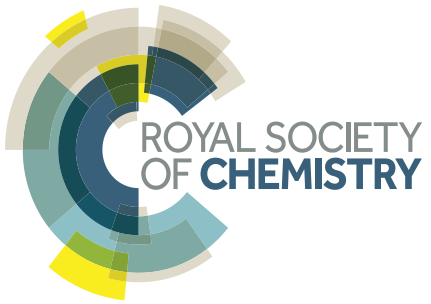




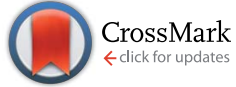

Cite this: J. Mater. Chem. A, 2016, 4, 5428

Received 9th January 2016

Accepted 29th January 2016

DOI: $10.1039 / c 6 t a 00236 f$

www.rsc.org/MaterialsA

\section{Superior sodium-ion storage performance of $\mathrm{CO}_{3} \mathrm{O}_{4}$ @ nitrogen-doped carbon: derived from a metal-organic framework $\uparrow$}

\begin{abstract}
Ying Wang, ${ }^{\text {ad }}$ Caiyun Wang, ${ }^{b}$ Yijing Wang, ${ }^{\text {*ac Huakun Liu }}{ }^{d}$ and Zhenguo Huang*d
Nitrogen-doped carbon coated $\mathrm{CO}_{3} \mathrm{O}_{4}$ nanoparticles $\left(\mathrm{CO}_{3} \mathrm{O}_{4} @ \mathrm{NC}\right)$ with high $\mathrm{Na}$-ion storage capacity and unprecedented long-life cycling stability are reported in this paper. The $\mathrm{CO}_{3} \mathrm{O}_{4} @ \mathrm{NC}$ was derived from a metal-organic framework ZIF-67, where the Co ions and organic linkers were, respectively, converted to $\mathrm{CO}_{3} \mathrm{O}_{4}$ nanoparticle cores and nitrogen-doped carbon shells through a controlled two-step annealing process. The $\mathrm{CO}_{3} \mathrm{O}_{4}$ @NC shows a porous nature with a surface area of $101 \mathrm{~m}^{2} \mathrm{~g}^{-1}$. When applied as an anode for sodium ion batteries (SIBs), $\mathrm{CO}_{3} \mathrm{O}_{4}$ @NC delivers a high reversible capacity of 506, 317, and 263 $\mathrm{mA} \mathrm{h} \mathrm{g}{ }^{-1}$ at 100,400 , and $1000 \mathrm{~mA} \mathrm{~g}^{-1}$, respectively. A capacity degradation of $0.03 \%$ per cycle over 1100 cycles was achieved at a high current density of $1000 \mathrm{~mA} \mathrm{~g}^{-1}$. The outstanding $\mathrm{Na}$-ion storage performance can be ascribed to the nitrogen-doped carbon coating (NC), which facilitates the capacitive reaction, minimizes the volume changes of $\mathrm{CO}_{3} \mathrm{O}_{4}$, and also enhances the electronic conductivity. This work sheds light on how to develop high-performance metal oxide@NC nanocomposites for SIBs.
\end{abstract}

\section{Introduction}

Sodium ion batteries (SIBs) have drawn enormous attention for applications in large-scale energy storage such as smart grids, due to their low cost and the wide natural availability of $\mathrm{Na}^{1-3}$ Similar to lithium ion batteries (LIBs), Na-ion storage normally occurs via three types of reactions: insertion, alloying, and conversion. Among these reactions, the conversion type generally involves a multi-electron reaction, which contributes to high capacity and consequently attracts great research attention. The conversion reactions, however, are accompanied by large volume changes during the sodiation/desodiation, which result in agglomeration or pulverization, and thus capacity decay and poor cycle life., ${ }^{1,4}$ In addition, the poor electron conductivity of the matrix leads to unsatisfactory rate capability. ${ }^{5} \mathrm{~A}$ great deal of effort is obviously necessary to improve the electrochemical performance of conversion-type reactions.

One highly effective way to improve the cycling and rate performance of conversion-type materials is to coat the metal oxides with carbon materials, ${ }^{6,7}$ which can effectively

\footnotetext{
${ }^{a}$ Key Laboratory of Advanced Energy Materials Chemistry, Nankai University, Tianjin, 300071, China.E-mail:wangyj@nankai.edu.cn

${ }^{b}$ Intelligent Polymer Research Institute, ARC Centre of Excellence for Electromaterials Science, University of Wollongong, NSW 2500, Australia

'Collaborative Innovation Centre of Chemical Science and Engineering, Tianjin, 300071, China

${ }^{d}$ Institute for Superconducting and Electronic Materials, University of Wollongong, NSW 2500, Australia. E-mail: zhenguo@uow.edu.au

$\dagger$ Electronic Supplementary Information (ESI) available. See DOI: $10.1039 / \mathrm{c} 5$ ta00236f
}

accommodate the volume changes and improve the electronic conductivity. Incorporation of heteroatoms into carbon can not only provide more active sites, but also enhance the chemical wettability. ${ }^{8-10}$ Nitrogen, with higher electron negativity and a similar atomic diameter to carbon, is a highly attractive doping candidate for carbon. ${ }^{11-13}$ Reducing the particle size to the nanoscale is another common approach to improve the electrochemical performance, since it can effectively shorten the diffusion distance and provide more contact surfaces between the electrolyte and electrode. ${ }^{14,15}$ The combination of a heteroatom-doped carbon coating and nanostructure is therefore a sound strategy to develop high-performance hybrid composites for SIBs.

Metal-organic frameworks (MOFs), composed of metal ions and interconnected organic linkers, feature tunable porosities and versatile functionalities. ${ }^{16-18}$ Using MOFs as templates to prepare electrochemically active materials (porous carbons, metal oxides, metal oxide/carbons, etc.) has been rapidly explored for LIBs. ${ }^{19-26}$ For example, highly Ndoped porous carbon (derived from ZIF-8) showed a capacity of $2132 \mathrm{~mA} \mathrm{~h} \mathrm{~g}^{-1}$ after 50 cycles at $100 \mathrm{~mA} \mathrm{~g}^{-1}$ in LIBs. ${ }^{11}$ Spindle-like $\mathrm{Fe}_{2} \mathrm{O}_{3}$ (derived from MIL-88Fe) anodes exhibited excellent rate capability in $\mathrm{Li} / \mathrm{Fe}_{2} \mathrm{O}_{3}$ half cells. ${ }^{27}$ The successful applications of MOFs in LIBs have recently aroused attention in SIBs. ${ }^{28}$

In contrast to the previous methods, where either metal ions or organic linkers were used to obtain pure metal oxide or carbon products, ${ }^{20-24}$ we report a method to produce metal oxide@nitrogen doped carbon core-shell structures where both metal oxides and organic linkers of the MOF precursor are fully 
utilized. Herein, ZIF-67 is selected as a dynamic template, since the organic linkers in ZIF-67 contain both $\mathrm{N}$ and $\mathrm{C}$, a great source of NC; its metal ions $\mathrm{Co}^{2+}$ can be converted to $\mathrm{Co}_{3} \mathrm{O}_{4}$. When applied as an anode for SIBs, this unique $\mathrm{Co}_{3} \mathrm{O}_{4} @ \mathrm{NC}$ exhibits outstanding electrochemical performance with a high capacity ( $506 \mathrm{~mA} \mathrm{~h} \mathrm{~g}^{-1}$ at $100 \mathrm{~mA} \mathrm{~g}^{-1}$ ), and an ultralong cycling stability (a capacity degradation of $0.03 \%$ per cycle during 1100 cycles at $1000 \mathrm{~mA} \mathrm{~g}^{-1}$ ). This outstanding electrochemical performance can be attributed to the capacitive reaction and the full conversion between $\mathrm{Co}_{3} \mathrm{O}_{4}$ and Co. This approach can be easily transferred to develop other nanoscale metal oxides with N-doped carbon coatings for high-performance SIBs.

\section{Experimental}

\section{Preparation of the $\mathrm{Co}_{3} \mathrm{O}_{4} @ \mathrm{NC}$ and the pure $\mathrm{Co}_{3} \mathrm{O}_{4}$}

All chemicals were purchased from Sigma-Aldrich and used asreceived without further treatment. The ZIF-67 precursor was synthesized according to the literature. ${ }^{29,30}$ Typically, to successfully convert the ZIF-67 to $\mathrm{Co}_{3} \mathrm{O}_{4} @ \mathrm{NC}$, two steps were involved. ZIF-67 powders were first placed in a tube furnace and calcined at $550{ }^{\circ} \mathrm{C}$ for $2 \mathrm{~h}$ under $\mathrm{Ar}$ protection. The resultant sample was marked as Co@NC. The as-prepared Co@NC sample then underwent a controlled oxidization process by being held at $150{ }^{\circ} \mathrm{C}$ for $12 \mathrm{~h}$ in air. For comparison, ZIF-67 derived pure $\mathrm{Co}_{3} \mathrm{O}_{4}$ was also synthesized. To obtain the pure $\mathrm{Co}_{3} \mathrm{O}_{4}$, the $\mathrm{Co@NC}$ intermediate was further calcined at $350{ }^{\circ} \mathrm{C}$ in air for another $3 \mathrm{~h}$.

\section{Characterization}

$\mathrm{X}$-ray diffraction (XRD, GBC eMMA, $\mathrm{Cu} \mathrm{K} \alpha$ radiation, $\lambda=1.5406$ A), X-ray photoelectron spectroscopy (XPS, VG Scientific ESCALAB 2201XL, Al K $\alpha$ X-ray radiation), Fourier transform infrared spectroscopy (FTIR, Shimadzu prestige-21), thermogravimetric analysis-differential scanning calorimetry measurements (TGADSC, Mettler Toledo TGA/DSC1), Raman spectroscopy (JobinYvon HR800 Raman spectrometer with a $10 \mathrm{~mW}$ helium/neon laser at $632.8 \mathrm{~nm}$ excitation), and nitrogen adsorption-desorption isotherms (NOVA 2200e, Quantachrome Instruments) were used to determine the structure or composition. Scanning electron microscopy (SEM, JEOL JSM7500FA), transmission electron microscopy (TEM), selected area electron diffraction (SAED), and high-resolution TEM (HR-TEM, JEOL JEM2010FEF) were adopted for morphological and structural investigations.

\section{Electrochemical measurements}

The electrochemical performances were evaluated by using standard 2032 type coin cells. The working electrodes were fabricated with $80 \mathrm{wt} \%$ active materials, $10 \mathrm{wt} \%$ acetylene black (Super-P), and $10 \mathrm{wt} \%$ sodium carboxymethyl cellulose (CMC) in deionized water to form a slurry. The slurry was then cast onto copper foil and dried in a vacuum oven at $80{ }^{\circ} \mathrm{C}$ overnight. A sodium disc was used as the counter and reference electrodes. The electrodes were separated by a glass fiber. $1 \mathrm{M} \mathrm{NaClO}_{4}$ in propylene carbonate (PC) with the addition of $2 \mathrm{wt} \%$ fluoroethylene carbonate (FEC) was used as an electrolyte. The cells were assembled in an argon filled glovebox with oxygen and water content below 1 ppm. Galvanostatic charge-discharge tests were carried out on a battery testing system (Shenzhen NEWARE Battery, China) with the voltage between 0.01 and 3.00 V. Electrochemical impedance spectroscopy (EIS) measurements and cyclic voltammetry (CV) were performed on a Biologic VMP-3 electrochemical workstation. The capacities were calculated based on the active materials.

\section{Results and discussion}

The MOF derived $\mathrm{Co}_{3} \mathrm{O}_{4} @ N C$ is synthesized through a controlled two-step oxidation as illustrated in Fig. 1. ZIF-67 consists of $\mathrm{Co}^{2+}$ ions bonded with the $\mathrm{N}$ in 2-methylimidazole (organic linkers) (Fig. 1a). During the first step calcination the cobalt ions were converted into ultra-small metallic Co particles (Fig. 1b). Meanwhile, the organic linker was carbonized to NC that wraps the Co particles (Co@NC). By annealing Co@NC at $150{ }^{\circ} \mathrm{C}$ in air for $12 \mathrm{~h}$, the central Co particles were gradually oxidized to $\mathrm{Co}_{3} \mathrm{O}_{4},{ }^{31}$ while the $\mathrm{NC}$ shell survived at this relatively low temperature. The final sample (Fig. 1c) maintains the polyhedral outline of the precursor and is composed of coreshell $\mathrm{Co}_{3} \mathrm{O}_{4} @ \mathrm{NC}$ subunits.

The formation of the ZIF-67 precursor was confirmed by its X-ray diffraction (XRD) pattern (Fig. 2a) and Fourier transform infrared (FTIR) spectrum (Fig. S1, ESI $\dagger$ ). A temperature of $550{ }^{\circ} \mathrm{C}$ was chosen to anneal the ZIF-67 in Ar, since it demonstrated a dramatic weight loss between 500 and $650{ }^{\circ} \mathrm{C}$ (TGA curves, Fig. S2 $\dagger$ ). The first-step annealing led to the formation of metallic Co, which was subsequently converted to $\mathrm{Co}_{3} \mathrm{O}_{4}$ when heated at $150{ }^{\circ} \mathrm{C}$ in air for $12 \mathrm{~h}$ (Fig. 2a). XPS (Fig. 2b-e) reveals the presence of $\mathrm{C}, \mathrm{N}, \mathrm{O}$, and $\mathrm{Co}$ in the resultant sample. The high-resolution XPS spectrum of Co 2 p reveals two major peaks at 778.8 and $794.0 \mathrm{eV}$, and the $15.2 \mathrm{eV}$ energy difference between the Co $2 \mathrm{p}$ peaks is indicative of spinel $\mathrm{Co}_{3} \mathrm{O}_{4} \cdot{ }^{32}$ The presence of satellite peaks (marked as Sat. in Fig. 2c) further confirms the well-defined $\mathrm{Co}_{3} \mathrm{O}_{4}$ structure. ${ }^{33}$ The $\mathrm{C}$ 1s spectrum (Fig. 2d) indicates the presence of carbon, whose absence in the XRD pattern is due to its amorphous nature. Two types of nitrogen are observed in the $\mathrm{N}$ 1s spectrum (Fig. 2e), pyridinic and pyrrolic $\mathrm{N}$ at 399.1 and $400.6 \mathrm{eV}$, respectively. The presence of carbon in $\mathrm{Co}_{3} \mathrm{O}_{4} @ \mathrm{NC}$ is also evidenced by the characteristic $\mathrm{D}$ and $\mathrm{G}$ bands in the Raman spectrum (Fig. 2f). The carbon content of $\mathrm{Co}_{3} \mathrm{O}_{4} @ \mathrm{NC}$ is confirmed by using TGA curves (Fig. S3, $\dagger$ performed in air). The weight loss between 250 and $370{ }^{\circ} \mathrm{C}$ is associated with the combustion of NC. Therefore, the carbon content in $\mathrm{Co}_{3} \mathrm{O}_{4} @ \mathrm{NC}$ was evaluated to be about 26 $\mathrm{wt} \%$. The nitrogen content in carbon is $15.4 \%$ according to the elemental analysis report. Elemental content $(\mathrm{Co}, \mathrm{C}, \mathrm{N})$ is given in Table S1.†

The morphologies of the samples were characterized by scanning and transmission electron microscopy (SEM and TEM). The ZIF-67 precursors are in the form of polyhedron with smooth surfaces, and the typical particle size is $\sim 180 \mathrm{~nm}$ (Fig. 3a and b). The $\mathrm{Co}_{3} \mathrm{O}_{4}$ @NC particles inherit the contour of 


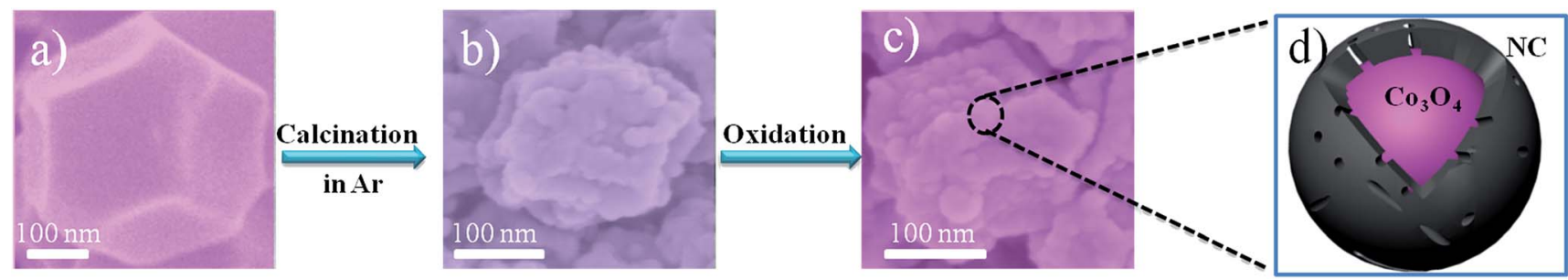

Fig. 1 Illustration of the formation of $\mathrm{CO}_{3} \mathrm{O}_{4}$ aNC. Scanning electron microscope (SEM) images of (a) ZIF-67 precursor, (b) Co@NC intermediate, and (c) $\mathrm{CO}_{3} \mathrm{O}_{4}$ (aNC. The subunit composition, consisting of a $\mathrm{CO}_{3} \mathrm{O}_{4}$ core and a NC shell, is illustrated in (d).
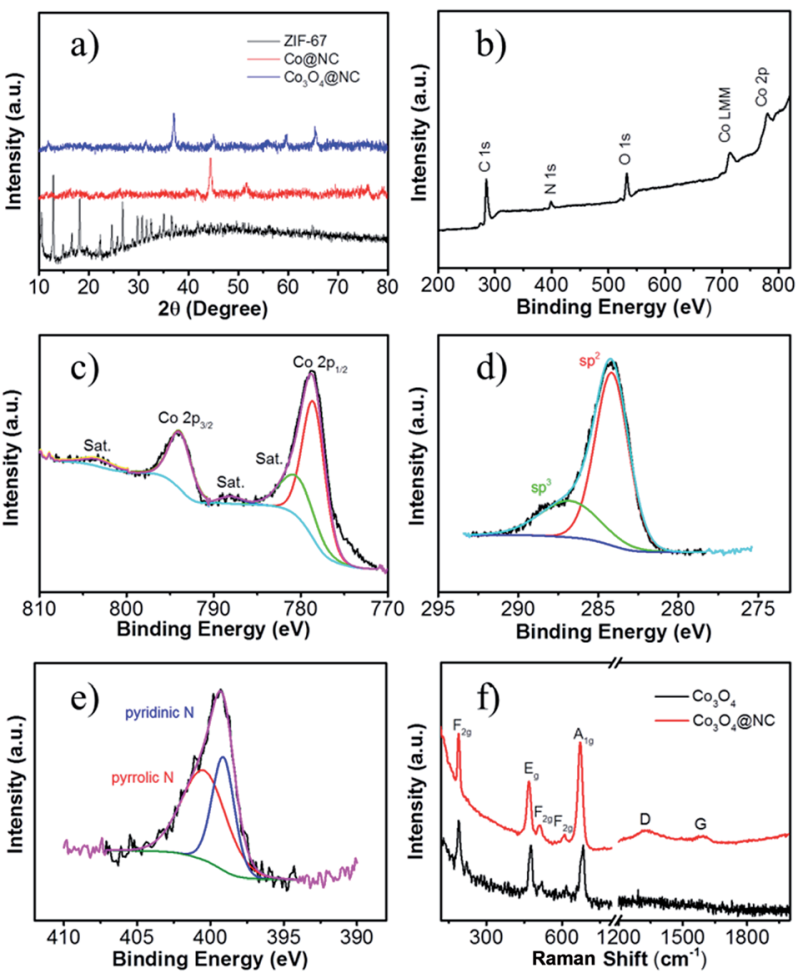

Fig. 2 (a) XRD patterns of ZIF-67, Co@NC, and $\mathrm{Co}_{3} \mathrm{O}_{4} @ \mathrm{aNC}$; (b) XPS survey spectrum of $\mathrm{CO}_{3} \mathrm{O}_{4} @ \mathrm{aNC}_{\text {; }}$ high resolution XPS spectra of (c) $\mathrm{Co}$ $2 \mathrm{p}$, (d) $\mathrm{C} 1 \mathrm{~s}$, and (e) $\mathrm{N}$ 1s of the $\mathrm{CO}_{3} \mathrm{O}_{4} @ \mathrm{NC}$; (f) Raman spectra of $\mathrm{CO}_{3} \mathrm{O}_{4}$ and $\mathrm{CO}_{3} \mathrm{O}_{4}$ aNC composites.

ZIF-67, but shrink to $100 \mathrm{~nm}$ (Fig. 3c). The $\mathrm{Co}_{3} \mathrm{O}_{4} @ N C$ polyhedron is composed of closely packed nanoparticles (NPs) that form a rough surface (Fig. 3d), which can also be observed in $\mathrm{Co@NC}$ and pure $\mathrm{Co}_{3} \mathrm{O}_{4}$ (derived from ZIF-67, ESI, Fig. S4 $\dagger$ ). ${ }^{34}$ The polyhedral morphology of the particles and the existence of subunits can be seen more clearly under TEM (Fig. 3e and f). A core-shell structure is clearly demonstrated for $\mathrm{Co}_{3} \mathrm{O}_{4} @ \mathrm{NC}$ in the high-resolution TEM image (Fig. 3f), where $\sim 5 \mathrm{~nm} \mathrm{Co}_{3} \mathrm{O}_{4}$ is the core and $2-3 \mathrm{~nm} \mathrm{NC}$ is the shell. The lattice fringe spacing of $2.8 \AA$ is related to the (220) planes of spinel $\mathrm{Co}_{3} \mathrm{O}_{4}$. The contrast profile of the NC shell displays a $d$-spacing of $3.8 \AA$, which corresponds to the $\mathrm{C}$ (002) planes (inset of Fig. $3 \mathrm{f}$ ). ${ }^{34}$ This could be beneficial since carbon materials enable more effective sodiation/desodiation when the interlayer distance is larger than $3.7 \AA^{34}$ The bright dots in the dark field TEM image (Fig. 3g) are $\mathrm{Co}_{3} \mathrm{O}_{4}$ NPs, and the dark part is interconnected NC.
The corresponding energy dispersive spectroscopy (EDS) mappings (Fig. 3h) show that all the elements are uniformly distributed.

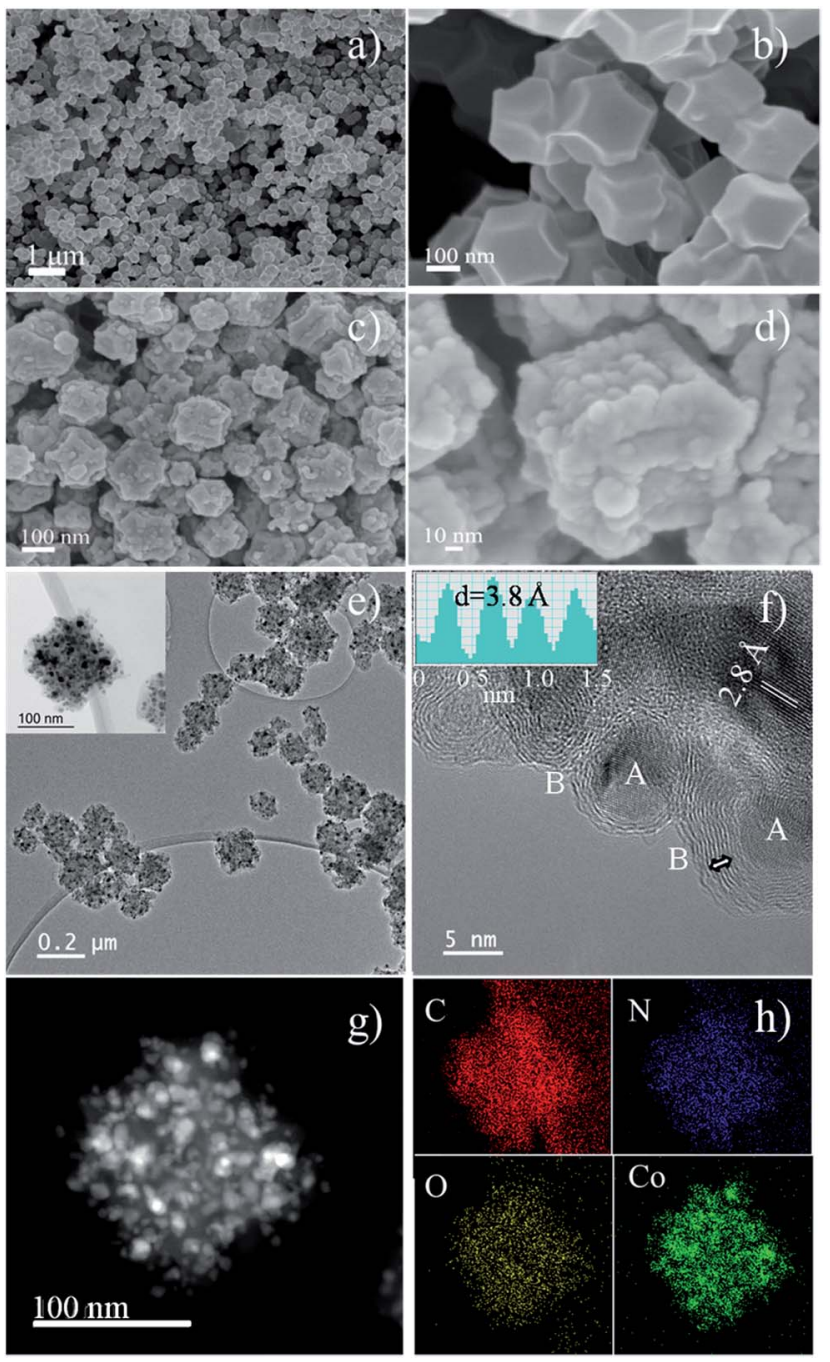

Fig. 3 SEM images of ( $a$ and b) ZIF-67 precursor; ( $c$ and d) as-obtained $\mathrm{CO}_{3} \mathrm{O}_{4}$ (aNC at different magnifications. TEM images of (e and $f$ ) $\mathrm{CO}_{3} \mathrm{O}_{4} @ \mathrm{NC}$ at different magnifications. $\mathrm{A}$ and $\mathrm{B}$ in ( $\mathrm{f}$ ) represent the $\mathrm{CO}_{3} \mathrm{O}_{4}$ core and the $\mathrm{NC}$ shell, respectively. The contrast profile in inset (f) is obtained from the NC shell from the region highlighted by a double-sided arrow. (g) Dark-field TEM image of a $\mathrm{CO}_{3} \mathrm{O}_{4}$ @NC polyhedron, and (h) the corresponding elemental mappings for $\mathrm{C}, \mathrm{N}$, $\mathrm{O}$, and Co. 
The surface area and pore size distribution can greatly affect the electrochemical performance. The nitrogen sorption isotherms of this $\mathrm{Co}_{3} \mathrm{O}_{4} @ \mathrm{NC}$ sample (Fig. 4) show a typical typeIV hysteresis loop, confirming its mesoporous nature which facilitates the contact between the electrode and electrolyte. The Brunauer-Emmett-Teller (BET) surface area of the $\mathrm{Co}_{3} \mathrm{O}_{4} @ N C$ is $101 \mathrm{~m}^{2} \mathrm{~g}^{-1}$. The decreased surface area, from ZIF-67 $\left(664 \mathrm{~m}^{2}\right.$ $\left.\mathrm{g}^{-1}\right)^{35}$ to $\mathrm{Co}_{3} \mathrm{O}_{4} @ \mathrm{NC}\left(101 \mathrm{~m}^{2} \mathrm{~g}^{-1}\right)$, was likely caused by the carbonization of organic linkers. The majority mesopores of the $\mathrm{Co}_{3} \mathrm{O}_{4} @ \mathrm{NC}$ are $\sim 5 \mathrm{~nm}$ in diameter that can be assigned to the pores in the shells, while the larger pores from 20 to $60 \mathrm{~nm}$ are likely related to the pores between polyhedra.

The sodium-ion storage performance of the $\mathrm{Co}_{3} \mathrm{O}_{4} @ \mathrm{NC}$ was investigated by assembling it into standard 2032 half-cells. Discharge-charge curves (at $100 \mathrm{~mA} \mathrm{~g}^{-1}$ ) of the $\mathrm{Co}_{3} \mathrm{O}_{4}$ and $\mathrm{Co}_{3} \mathrm{O}_{4} @ \mathrm{NC}$ electrodes are presented in Fig. $5 \mathrm{a}$ and b. The large capacity loss in the first cycle mainly arises from the decomposition of the electrolyte and the formation of the solid electrolyte interphase (SEI) film..$^{47,48}$ The first cycle discharge and charge capacities of the $\mathrm{Co}_{3} \mathrm{O}_{4} @ \mathrm{NC}$ electrode (813 and $516 \mathrm{~mA}$ $\mathrm{h} \mathrm{g}^{-1}$, respectively) are much higher than those of the pure $\mathrm{Co}_{3} \mathrm{O}_{4}$ electrode (495 and $326 \mathrm{~mA} \mathrm{~h} \mathrm{~g}^{-1}$ ). In the second cycle, the $\mathrm{Co}_{3} \mathrm{O}_{4} @ \mathrm{NC}$ electrode delivers a high capacity of $517 \mathrm{~mA} \mathrm{~h} \mathrm{~g}^{-1}$, much higher than $331 \mathrm{~mA} \mathrm{~h} \mathrm{~g}{ }^{-1}$ from $\mathrm{Co}_{3} \mathrm{O}_{4}$. This result outperforms not only the reported $\mathrm{Co}_{3} \mathrm{O}_{4}$ anodes, ${ }^{4-46}$ but also a large number of other materials, such as $\mathrm{Li}_{4} \mathrm{Ti}_{5} \mathrm{O}_{12} / \mathrm{C}, \mathrm{MoS}_{2}$, $\mathrm{Sn} @ \mathrm{C}$, and $\mathrm{Fe}_{2} \mathrm{O}_{3} \cdot{ }^{36,37,39,40,43,49,50}$ The higher capacity of $\mathrm{Co}_{3} \mathrm{O}_{4} @ \mathrm{NC}$ may derive from its defect rich structure and porous nature, which help to trap more $\mathrm{Na}^{+}$during the cycling. Additionally, the $\mathrm{N}$ doping provides more active sites for $\mathrm{Na}^{+}$storage and enhances the capacitive behaviour. ${ }^{11}$ Thus, this $\mathrm{Co}_{3} \mathrm{O}_{4} @ N C$ electrode exhibits a higher capacity. Another remarkable difference between the pure $\mathrm{Co}_{3} \mathrm{O}_{4}$ and the $\mathrm{Co}_{3} \mathrm{O}_{4} @ \mathrm{NC}$ is the reversible capacity contribution at a lower potential $(0.25-0.01$ V). Compared with the rapid decline of pure $\mathrm{Co}_{3} \mathrm{O}_{4}$, the $\mathrm{Co}_{3} \mathrm{O}_{4} @ \mathrm{NC}$ electrode contributes a large capacity of $\sim 185 \mathrm{~mA} \mathrm{~h}$ $\mathrm{g}^{-1}$ in this range, which is likely to be associated with the NC shell. ${ }^{34,51}$

The $\mathrm{Co}_{3} \mathrm{O}_{4} @ N C$ electrode also displays excellent cycling stability (Fig. 5c). A capacity of $\sim 373 \mathrm{~mA} \mathrm{~h} \mathrm{~g}{ }^{-1}$ was delivered at the end of 60 cycles ( $87.0 \%$ capacity retention), in contrast to the poor cycling stability of the $\mathrm{Co}_{3} \mathrm{O}_{4}$ electrode $(74.3 \%$ capacity retention). Superior rate capability is exhibited in the $\mathrm{Co}_{3} \mathrm{O}_{4} @ N C$ electrode (Fig. 5d), which shows an average capacity
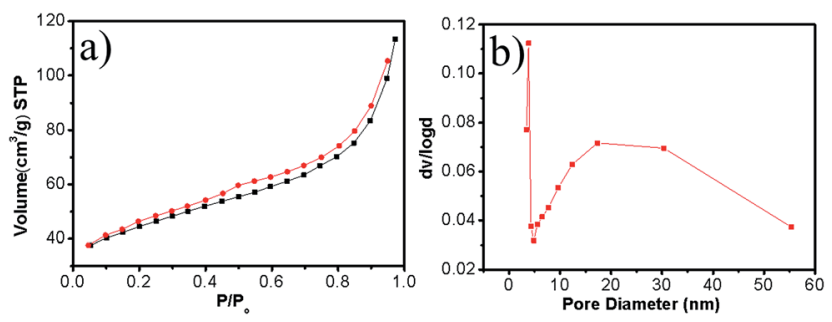

Fig. 4 (a) Nitrogen absorption-desorption isotherms, and (b) the corresponding pore size distribution curve of the $\mathrm{CO}_{3} \mathrm{O}_{4}$ @ NC sample.
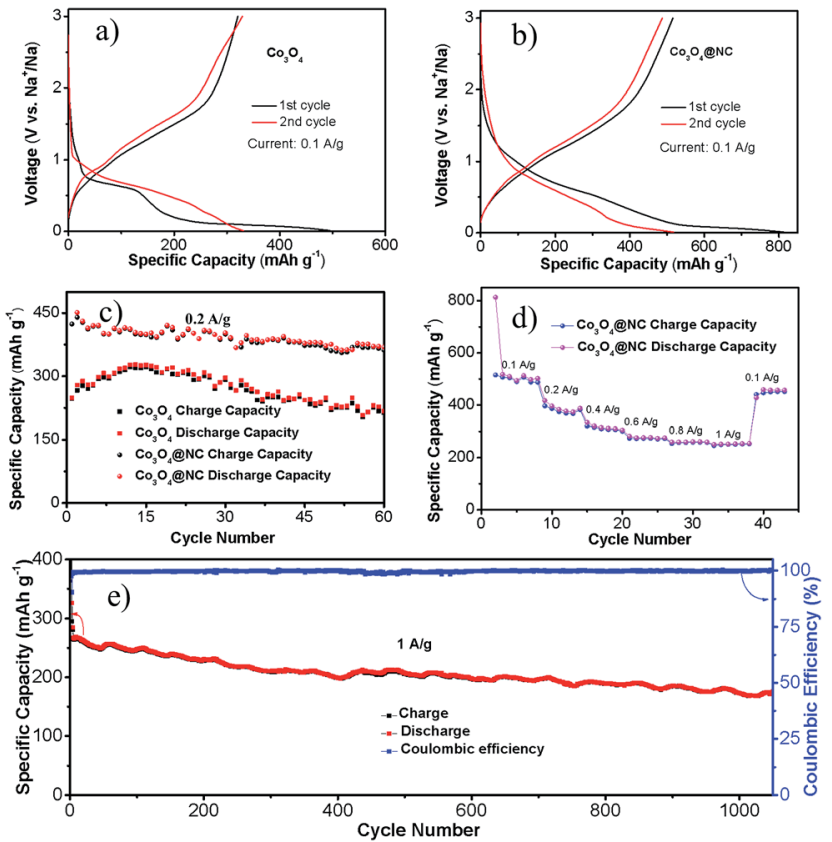

Fig. 5 The first and second discharge-charge curves of (a) pure $\mathrm{CO}_{3} \mathrm{O}_{4}$ and (b) $\mathrm{CO}_{3} \mathrm{O}_{4}$ @NC composites at $100 \mathrm{~mA} \mathrm{~g}^{-1}$. (c) Discharge and charge capacity of pure $\mathrm{CO}_{3} \mathrm{O}_{4}$ and $\mathrm{CO}_{3} \mathrm{O}_{4}$ @ NC electrodes for the first 60 cycles at $200 \mathrm{~mA} \mathrm{~g}^{-1}$. (d) Rate capability and (e) long-term cycling stability of $\mathrm{CO}_{3} \mathrm{O}_{4}$ @ NC electrode.

of 317,276 , and $263 \mathrm{~mA} \mathrm{~h} \mathrm{~g}{ }^{-1}$ at 400,800 , and $1000 \mathrm{~mA} \mathrm{~g}^{-1}$, respectively. When the current density was reversed back to 100 $\mathrm{mA} \mathrm{g}^{-1}$, a capacity of $457 \mathrm{~mA} \mathrm{~h} \mathrm{~g}^{-1}$ was obtained, $92 \%$ of the initial capacity. A direct comparison of the capacity retention at each current density is given in Fig. S5.† Exceptional long-term cycling stability was observed for the $\mathrm{Co}_{3} \mathrm{O}_{4} @ \mathrm{NC}$ electrode. It delivers a high reversible capacity of $175 \mathrm{~mA} \mathrm{~h} \mathrm{~g}^{-1}$ after 1100 cycles at a high specific current density of $1000 \mathrm{~mA} \mathrm{~h} \mathrm{~g}^{-1}$ (Fig. 5e), with a capacity decay of only $0.03 \%$ per cycle. Such an outstanding cycling stability is comparable or even better than the best electrodes reported (Table 1), especially for conversionbased Na-ion storage. Conversion reactions are generally companied by large volume changes and structural disintegration, which lead to poor cycling stability. Compared with large particles, this hierarchical structure is known to alleviate the negative impact due to volume changes. ${ }^{29,52}$ Furthermore, the carbon coating serves as a buffer and helps to maintain structural integrity. ${ }^{53,54}$ The as-obtained metal oxide@NC therefore is responsible for the outstanding cycling stability.

The existence of capacitive behaviour is beneficial for the cycling stability and rate capability in both LIBs and SIBs. However, it has been rarely mentioned in $\mathrm{Na} / \mathrm{Co}_{3} \mathrm{O}_{4}$ based cells. The contribution of the capacitive reaction in the $\mathrm{Co}_{3} \mathrm{O}_{4} @ \mathrm{NC}$ electrode was investigated in this work. Cyclic voltammetry curves (CVs, after the first cycle) at various scan rates were collected (Fig. 6a). Two peaks, marked as A and B, appeared during the sodiation and desodiation processes. The power-law relationship used to calculate the capacitive effect is illustrated in eqn (1) and (2). ${ }^{55}$ Herein, $i$ is the current, $v$ is the scan rate, 
Table 1 Electrochemical performance comparison of the $\mathrm{Co}_{3} \mathrm{O}_{4} @ \mathrm{NC}$ electrode with some typical anode materials for SIBs

\begin{tabular}{|c|c|c|c|c|}
\hline Electrode & Current $\left(\mathrm{mA} \mathrm{g}^{-1}\right)$ & Capacity $\left(\mathrm{mA} \mathrm{h} \mathrm{g}^{-1}\right)$ & Capacity retention & Ref/year \\
\hline $\mathrm{Li}_{4} \mathrm{Ti}_{5} \mathrm{O}_{12} / \mathrm{C}$ & 35 & 168 & $96 \%$ after 50 cycles & $36 / 2015$ \\
\hline${ }^{a} \mathrm{PEO}-\mathrm{MoS}_{2}$ & 50 & 148 & $66 \%$ after 70 cycles & $37 / 2015$ \\
\hline $\mathrm{Al}_{2} \mathrm{O}_{3} / \mathrm{SnO}_{2} / \mathrm{CC}$ & 134 & 377 & $80 \%$ after 100 cycles & $39 / 2015$ \\
\hline $\mathrm{Fe}_{2} \mathrm{O}_{3}$ & 100 & 386 & $73 \%$ after 200 cycles & $40 / 2014$ \\
\hline $\mathrm{CuO}$ & 50 & 303 & $64 \%$ after 50 cycles & $41 / 2013$ \\
\hline $\mathrm{Co}_{3} \mathrm{O}_{4}$ bowl & 890 & 290 & $22 \%$ after 10 cycles & $44 / 2014$ \\
\hline Meso- $\mathrm{Co}_{3} \mathrm{O}_{4}$ & 455 & $\sim 130$ & $44 \%$ after 250 cycles & $45 / 2014$ \\
\hline${ }^{c} \mathrm{Co}_{3} \mathrm{O}_{4}-\mathrm{MCNTS}$ & 34 & 293 & $36 \%$ after 15 cycles & $46 / 2015$ \\
\hline $\mathrm{Co}_{3} \mathrm{O}_{4} @ \mathrm{NC}$ & 1000 & 175 & $67 \%$ after 1100 cycles & This worl \\
\hline
\end{tabular}

${ }^{a}$ PEO: poly(ethylene oxide). ${ }^{b}$ NPs: nanoparticles. ${ }^{c}$ MCNTs: multiwall carbon nanotubes.
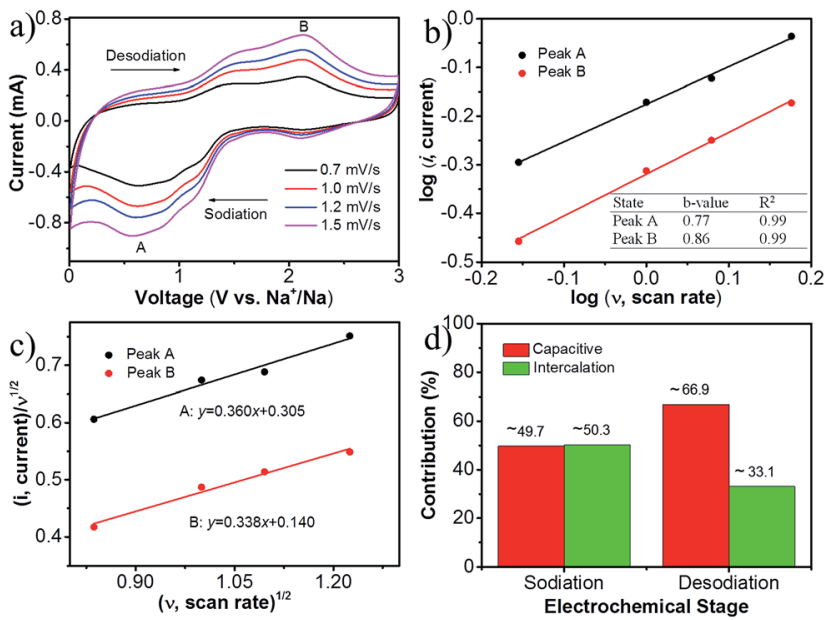

Fig. 6 (a) $\mathrm{CV}$ curves (after the first cycle) of the $\mathrm{Na} / \mathrm{Co}_{3} \mathrm{O}_{4}$ (aNC halfcells at different scan rates, (b) $\log i$ vs. $\log v$ plots used to qualify the electrochemical reaction, (c) relationship between the peak current and the scan rate used to quantify the contribution of the capacitive reaction, and (d) quantitative contributions for each type of electrochemical behavior.

and $a$ and $b$ are adjustable values. When $b$ is close to 0.5 , the electrochemical reaction is dominated by a diffusion (or faradaic) process; when $b$ approaches 1 , the system features a surface-limited capacitive (or non-faradic) reaction. In the $\log i v s . \log v$ plot (Fig. 6b), $b$ is calculated to be 0.77 and 0.86 for the reduction (peak A) and oxidation (peak B), respectively, indicating combined faradaic and non-faradaic processes.

$$
\begin{gathered}
i=a v^{b} \\
\log i=b \times \log v+\log a
\end{gathered}
$$

To quantify the contributions from the faradaic and nonfaradaic behaviour, eqn (3) was used, ${ }^{47,56}$ where $k_{1} V$ is the capacitive component and $k_{2} V^{1 / 2}$ is the intercalation component. In the plots of $i / V^{1 / 2} v s$. $V_{1 / 2}$ (Fig. 6c), the slope represents constant $k_{1}$, and the intercept stands for constant $k_{2}$. The percentages of faradaic and non-faradaic reactions that occurred in the electrochemical process were extrapolated (Fig. 6d). The capacitive reaction became dominant during desodiation. The pseudo-capacitive reaction at the surface is conducive to high rate capability and long-term cycling stability. ${ }^{55,57}$ This explains the outstanding Na-ion storage performance of $\mathrm{Co}_{3} \mathrm{O}_{4} @ \mathrm{NC}$.

$$
i=k_{1} v+k_{2} v^{1 / 2}
$$

Electrochemical impedance spectroscopy (EIS) was used to confirm the existence of the capacitive process and to investigate the kinetics in the $\mathrm{Co}_{3} \mathrm{O}_{4}$ @NC electrode (Fig. 7). All the Nyquist plots contain a depressed semicircle in the medium to high frequency range, followed by a straight line. Generally, the more vertical the straight line is, the more capacitive the behaviour is. ${ }^{56}$ The phase angle of each electrode is in the following order: the cycled $\mathrm{Co}_{3} \mathrm{O}_{4} @ \mathrm{NC}\left(\sim 73^{\circ}\right)>$ pristine $\mathrm{Co}_{3} \mathrm{O}_{4} @ \mathrm{NC}\left(\sim 59^{\circ}\right)>$ pristine $\mathrm{Co}_{3} \mathrm{O}_{4}\left(\sim 46^{\circ}\right)$. Accordingly, the following conclusions can be drawn: (1) the capacitive process in $\mathrm{Co}_{3} \mathrm{O}_{4} @ \mathrm{NC}$ mainly originates from the NC shell, since the pure $\mathrm{Co}_{3} \mathrm{O}_{4}$ demonstrates negligible capacitive behaviour (a phase angle of $46^{\circ}$, close to $45^{\circ}$ ). The $\mathrm{N}$-containing functional

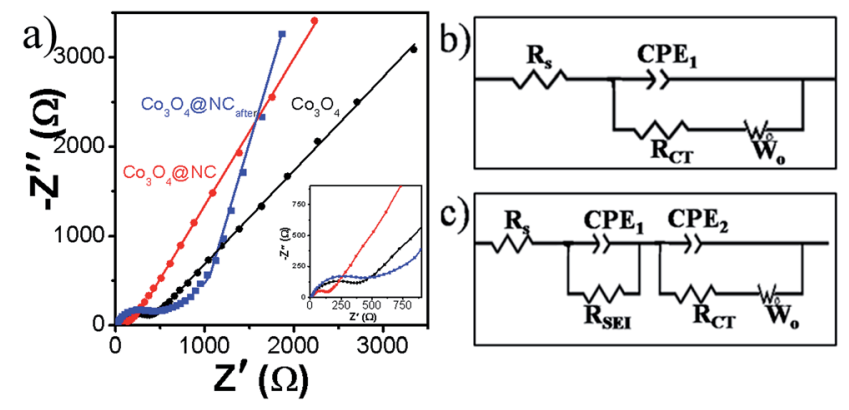

Fig. 7 (a) Electrochemical impedance spectroscopy of the pristine $\mathrm{CO}_{3} \mathrm{O}_{4}, \mathrm{CO}_{3} \mathrm{O}_{4} @ \mathrm{aNC}$, and $\mathrm{CO}_{3} \mathrm{O}_{4}$ (aNC electrodes after 1100 cycles, tested in the fully charged state. Equivalent circuits of (b) the pristine cells and (c) the cycled cells. 
groups (pyridinic and pyrrolic $\mathrm{N}$ ) in the $\mathrm{NC}$ facilitate the capacitive properties. ${ }^{11}$ (2) The capacitive behaviour in the $\mathrm{Co}_{3} \mathrm{O}_{4} @ \mathrm{NC}$ sample becomes more dominant with cycling. To calculate the resistance, the related equivalent circuits are given in Fig. $7 \mathrm{~b}$ and c. Here, $R_{\mathrm{S}}, R_{\mathrm{CT}}, R_{\mathrm{SEI}}, \mathrm{CPE}$, and $W_{\mathrm{o}}$ represent the resistance related to the electrolyte, charge-transfer, and the SEI, the constant phase element(s), and the Warburg impedance associated with $\mathrm{Na}^{+}$diffusion, respectively. Compared to the pure $\mathrm{Co}_{3} \mathrm{O}_{4}\left(R_{\mathrm{CT}}=376 \Omega\right)$, the $\mathrm{Co}_{3} \mathrm{O}_{4} @ \mathrm{NC}$ shows a much smaller $R_{\mathrm{CT}}$ value of $164 \Omega$. The reduced $R_{\mathrm{CT}}$ can facilitate the kinetics and consequently improve the rate capability.

CVs were collected to obtain more information on the electrochemical reactions (Fig. $\mathrm{S} 7 \dagger$ ). There is a pair of broad redox peaks at about $0.6 / 1.4 \mathrm{~V}$, except for the first cycle. Previous reports vaguely attributed this to reversible reduction and oxidation between $\mathrm{Co}_{3} \mathrm{O}_{4}$ and metallic Co. ${ }^{43}$ Herein, to gain a clearer understanding of the electrochemical mechanism, ex situ XRD and high resolution (HR)-TEM were carried out. Fig. 8a displays the typical discharge-charge profile of the $\mathrm{Na}$ / $\mathrm{Co}_{3} \mathrm{O}_{4} @ \mathrm{NC}$ half cells in the first cycle. The plateaus at $\sim 0.6 \mathrm{~V}$ in the discharge process and $\sim 1.4 \mathrm{~V}$ in the charge process are in agreement with the $\mathrm{CV}$ results. Accordingly, five points, A (initial), B (discharged to $0.6 \mathrm{~V}$ ), C (discharged to $0.01 \mathrm{~V}$ ), D (charged to $1.4 \mathrm{~V}$ ), and $\mathrm{E}$ (charged to $3.0 \mathrm{~V}$ ), were selected to study the structural evolution during the electrochemical reaction. The strong reflections of $\mathrm{Cu}$ in the ex situ XRD patterns (Fig. 8b) are from the current collector. During the discharge process, the $\mathrm{Co}_{3} \mathrm{O}_{4}$ phase gradually disappeared while a new phase of $\mathrm{CoO}$ appeared when the cell was discharged to $0.6 \mathrm{~V}$. In the fully discharged state, only reflections belonging to $\mathrm{Cu}$ were observed. The following charge process experienced the reverse trend, with the presence of both $\mathrm{CoO}$ and $\mathrm{Co}_{3} \mathrm{O}_{4}$ at $1.4 \mathrm{~V}$, and then only $\mathrm{Co}_{3} \mathrm{O}_{4}$ at $3.0 \mathrm{~V}$. The XRD patterns do not reveal the $\mathrm{Na}_{2} \mathrm{O}$ phase, which may be ascribed to its poor crystallization and/or small particle size. Ex situ TEM images were also collected at the corresponding potentials in Fig. 8c. The TEM image of the pristine $\mathrm{Co}_{3} \mathrm{O}_{4} @ \mathrm{NC}$ electrode at $\mathrm{A}$ shows the typical lattice fringes with $4.7 \AA$ spacing for the $\mathrm{Co}_{3} \mathrm{O}_{4}$ (111) planes, and $3.8 \AA$ for the $\mathrm{C}$ (002) planes of the NC. When discharged to state B, an interlayer distance of $2.1 \AA$ was observed, which is related to the CoO (200) planes. After further discharging to state $\mathrm{C}$, elemental Co emerges, as evidenced by its (111) and (200) planes. The absence of Co from the XRD patterns may be due to its relatively poor crystallinity, and/or small particle size. ${ }^{42}$ The $d$-spacing of $3.2 \AA$ is ascribed to the (111) planes of $\mathrm{Na}_{2} \mathrm{O}^{41,42}$ During the charge reactions, both $\mathrm{CoO}$ and $\mathrm{Co}_{3} \mathrm{O}_{4}$ were detected at state $\mathrm{D}$, while at state $\mathrm{E}, \mathrm{Co}_{3} \mathrm{O}_{4}$ was the dominant phase. The EDS mapping indicates the presence of Co, Na, O, C, and $\mathrm{N}$ in the full discharged state (Fig. 9). The observation of the $\mathrm{CoO}$ intermediate during the process agrees with a report on $\mathrm{Li} / \mathrm{Co}_{3} \mathrm{O}_{4}$ half cells ${ }^{58}$ and explains the existence of the shoulder peaks in the CVs. Importantly, after full discharge the $\mathrm{Co}_{3} \mathrm{O}_{4} @ \mathrm{NC}$ can maintain its outline, and the NC
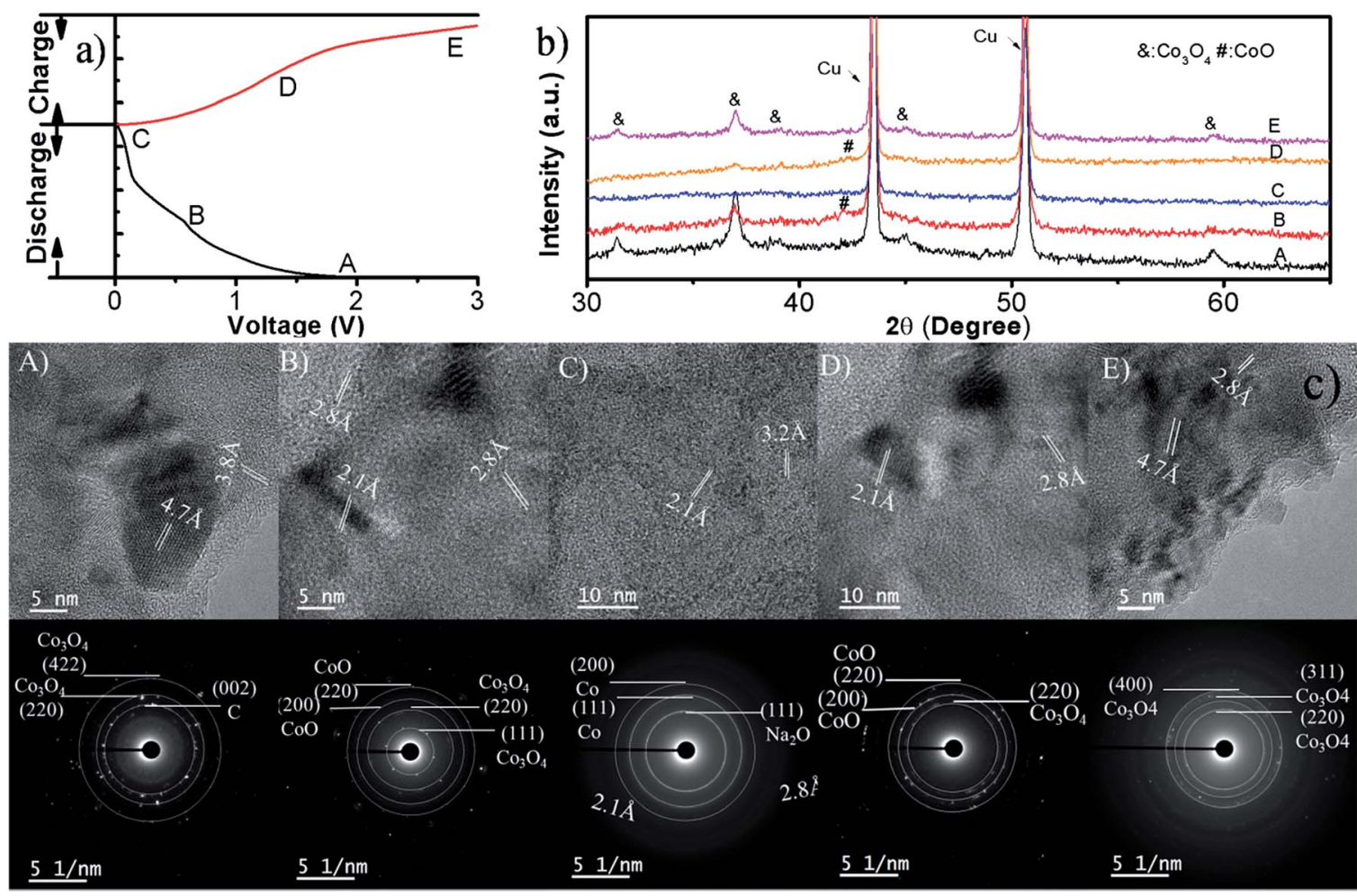

Fig. 8 Structural evolution of the $\mathrm{CO}_{3} \mathrm{O}_{4}$ aNC electrode during the electrochemical reaction. (a) Typical galvanostatic charge-discharge curve. Points A, B, C, D, and E represent the pristine state, the discharged state at $0.6 \mathrm{~V}$ and $0.01 \mathrm{~V}$, and the charged state at $1.4 \mathrm{~V}$ and $3.0 \mathrm{~V}$, respectively. (b) Ex situ XRD patterns corresponding to these points, and (c) TEM images (top) and selected area electron diffraction (SAED) patterns (bottom) at the corresponding points. 


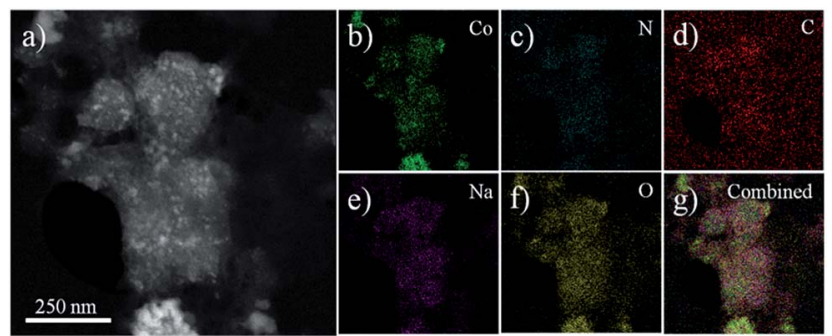

Fig. 9 (a) Dark field TEM image, and $(b-g)$ the corresponding EDS mappings of the $\mathrm{CO}_{3} \mathrm{O}_{4} @ \mathrm{NC}$ electrode in the fully discharged state.

shell (dark part) effect protects the $\mathrm{Co}_{3} \mathrm{O}_{4} \mathrm{NPs}$ (bright dots) from aggregation.

Based on the above discussion, the excellent Na-ion storage performance of $\mathrm{Co}_{3} \mathrm{O}_{4} @ \mathrm{NC}$ can be attributed to the following reasons. First, the complete encapsulation of the $\mathrm{Co}_{3} \mathrm{O}_{4} \mathrm{NPs}(\sim 5$ $\mathrm{nm}$ ) in the NC shell prevents the aggregation and pulverization of these NPs during cycling (Fig. $3 \mathrm{~g}$ and 9a). Second, the NC shell formed in situ can not only effectively accommodate the volume changes but also decrease the charge transfer resistance. The interconnected organic linkers in the MOF precursor would contribute to the formation of the $\mathrm{NC}$ shell with high integrity, which helps to maintain the structure during the sodiation/desodiation. Third, the electrochemical reactivity features a large capacity that is mainly contributed by the NC shells, which leads to high rate capability and outstanding longterm stability. Such capacitive behaviour has not been reported in $\mathrm{Co}_{3} \mathrm{O}_{4}$-based SIBs.

\section{Conclusions}

In summary, $\mathrm{Co}_{3} \mathrm{O}_{4} @ \mathrm{NC}$ was synthesized using ZIF-67 as the precursor and a dynamic template to obtain the desired morphology. During a controlled two-step calcination process, the central metal ions were transformed into $\mathrm{Co}_{3} \mathrm{O}_{4}$ NPs $(\sim 5$ $\mathrm{nm})$. The organic linkers were carbonized to form interconnected nitrogen-doped carbon layers $(2-3 \mathrm{~nm})$ on these $\mathrm{Co}_{3} \mathrm{O}_{4}$ NPs. The resultant $\mathrm{Co}_{3} \mathrm{O}_{4} @ \mathrm{NC}$ exhibits excellent Na-ion storage performance with high capacity and ultra-long cycling stability, which can be ascribed to the existence of capacitive behaviour and the full conversion between $\mathrm{Co}_{3} \mathrm{O}_{4}$ and metallic Co during the sodiation/desodiation. Ex situ XRD and TEM measurements reveal the electrochemical process during the cycling. This work points to a strategy to effectively improve the performance of conversion based Na-ion anode materials by using N-doped carbon coated metal oxide (MO@NC), particularly those derived from MOFs.

\section{Acknowledgements}

This work was financially supported by grants from the 973 Program (China) (2011CB935900), the National Science Foundation of China (NSFC) (21231005), the Ministry of Education (MOE) of China (IRT13R30), the 111 Project (B12015), the Research Fund for the Doctoral Program of Higher Education of
China (20120031110001), and the Tianjin Science \& Technology Project (10SYSYJC27600). Y. Wang thanks the China Scholarship Council (CSC) for scholarship support. Z. H. is a recipient of an Australian Research Council's Discovery Early Career Researcher Award (project number DE120101496). This research used equipment funded by the Australian Research Council (ARC) through a Linkage, Infrastructure, Equipment and Facilities (LIEF) grant (LE0882813) for facilities located at the UOW Electron Microscopy Centre.

\section{Notes and references}

1 X. Xiang, K. Zhang and J. Chen, Adv. Mater., 2015, 27, 53435364.

2 H. Kim, J. Hong, G. Yoon, H. Kim, K.-Y. Park, M.-S. Park, W.-S. Yoon and K. Kang, Energy Environ. Sci., 2015, 8, 2963-2969.

3 F. Wang, X. Wang, Z. Chang, X. Wu, X. Liu, L. Fu, Y. Zhu, Y. Wu and W. Huang, Adv. Mater., 2015, 27, 6962-6968.

$4 \mathrm{~J}$. Cabana, L. Monconduit, D. Larcher and M. R. Palacín, $A d v$. Mater., 2010, 22, E170-E192.

5 M. R. Palacín, Chem. Soc. Rev., 2009, 38, 2565.

6 S.-M. Oh, J.-Y. Hwang, C. S. Yoon, J. Lu, K. Amine, I. Belharouak and Y.-K. Sun, ACS Appl. Mater. Interfaces, 2014, 6, 11295-11301.

7 Y.-X. Wang, Y.-G. Lim, M.-S. Park, S.-L. Chou, J. H. Kim, H.-K. Liu, S.-X. Dou and Y.-J. Kim, J. Mater. Chem. A, 2014, 2, 529-534.

8 C. Ling and F. Mizuno, Phys. Chem. Chem. Phys., 2014, 16, 10419-10424.

9 J. Sun, G. Zheng, H.-W. Lee, N. Liu, H. Wang, H. Yao, W. Yang and Y. Cui, Nano Lett., 2014, 14, 4573-4580.

10 J. Xu, I.-Y. Jeon, J.-M. Seo, S. Dou, L. Dai and J.-B. Baek, Adv. Mater., 2014, 26, 7317-7323.

11 F. Zheng, Y. Yang and Q. Chen, Nat. Commun., 2014, 5, 5261.

12 Z. Wang, L. Qie, L. Yuan, W. Zhang, X. Hu and Y. Huang, Carbon, 2013, 55, 328-334.

13 J. Xu, M. Wang, N. P. Wickramaratne, M. Jaroniec, S. Dou and L. Dai, Adv. Mater., 2015, 27, 2042-2048.

14 J.-Y. Hwang, S.-T. Myung, J.-H. Lee, A. Abouimrane, I. Belharouak and Y.-K. Sun, Nano Energy, 2015, 16, 218-226.

15 Q. Zhang, E. Uchaker, S. L. Candelaria and G. Cao, Chem. Soc. Rev., 2013, 42, 3127-3171.

16 Q.-L. Zhu and Q. Xu, Chem. Soc. Rev., 2014, 43, 5468-5512. 17 S.-H. Park and W.-J. Lee, J. Power Sources, 2015, 281, 301-309. 18 Y. Zhao, Z. Song, X. Li, Q. Sun, N. Cheng, S. Lawes and X. Sun, Energy Storage Materials, 2016, 2, 35-62.

19 J. Shao, Z. Wan, H. Liu, H. Zheng, T. Gao, M. Shen, Q. Qu and H. Zheng, J. Mater. Chem. A, 2014, 2, 12194-12200.

20 G. Huang, F. Zhang, L. Zhang, X. Du, J. Wang and L. Wang, J. Mater. Chem. A, 2014, 2, 8048-8053.

21 F. Zheng, D. Zhu, X. Shi and Q. Chen, J. Mater. Chem. A, 2015, 3, 2815-2824.

22 R. Wu, X. Qian, F. Yu, H. Liu, K. Zhou, J. Wei and Y. Huang, J. Mater. Chem. A, 2013, 1, 11126-11129.

23 J. Ma, H. Wang, X. Yang, Y. Chai and R. Yuan, J. Mater. Chem. A, 2015, 3, 12038-12043. 
24 Z. Li and L. Yin, J. Mater. Chem. A, 2015, 3, 21569-21577.

25 C. Li, T. Chen, W. Xu, X. Lou, L. Pan, Q. Chen and B. Hu, J. Mater. Chem. A, 2015, 3, 5585-5591.

26 Y. Han, M. Zhao, L. Dong, J. Feng, Y. Wang, D. Li and X. Li, J. Mater. Chem. A, 2015, 3, 22542-22546.

27 X. Xu, R. Cao, S. Jeong and J. Cho, Nano Lett., 2012, 12, 49884991.

28 P. Nie, L. Shen, G. Pang, Y. Zhu, G. Xu, Y. Qing, H. Dou and X. Zhang, J. Mater. Chem. A, 2015, 3, 16590-16597.

29 Y. Wang, B. Wang, F. Xiao, Z. Huang, Y. Wang, C. Richardson, Z. Chen, L. Jiao and H. Yuan, J. Power Sources, 2015, 298, 203-208.

30 N. Yabuuchi, K. Kubota, M. Dahbi and S. Komaba, Chem. Rev., 2014, 114, 11636-11682.

31 A. Navrotsky, C. Ma, K. Lilova and N. Birkner, Science, 2010, 330, 199-201.

32 Y. Fan, N. Zhang, L. Zhang, H. Shao, J. Wang, J. Zhang and C. Cao, J. Electrochem. Soc., 2013, 160, F218-F223.

33 R. Xu and H. C. Zeng, Langmuir, 2004, 20, 9780-9790.

34 Y. Cao, L. Xiao, M. L. Sushko, W. Wang, B. Schwenzer, J. Xiao, Z. Nie, L. V. Saraf, Z. Yang and J. Liu, Nano Lett., 2012, 12, 3783-3787.

35 W. Sun, X. Zhai and L. Zhao, Chem. Eng. J., 2016, 289, 59-64.

36 K.-T. Kim, C.-Y. Yu, C. S. Yoon, S.-J. Kim, Y.-K. Sun and S.-T. Myung, Nano Energy, 2015, 12, 725-734.

37 Y. Li, Y. Liang, F. C. Robles Hernandez, H. Deog Yoo, Q. An and Y. Yao, Nano Energy, 2015, 15, 453-461.

38 Y. Liu, N. Zhang, L. Jiao, Z. Tao and J. Chen, Adv. Funct. Mater., 2015, 25, 214-220.

39 Y. Liu, X. Fang, M. Ge, J. Rong, C. Shen, A. Zhang, H. A. Enaya and C. Zhou, Nano Energy, 2015, 16, 399-407.

40 Y. Jiang, M. Hu, D. Zhang, T. Yuan, W. Sun, B. Xu and M. Yan, Nano Energy, 2014, 5, 60-66.

41 L. Wang, K. Zhang, Z. Hu, W. Duan, F. Cheng and J. Chen, Nano Res., 2014, 7, 199-208.

42 M. M. Rahman, A. M. Glushenkov, T. Ramireddy and Y. Chen, Chem. Commun., 2014, 50, 5057-5060.
43 Y. G. Liu, Z. Y. Cheng, H. Y. Sun, H. Arandiyan, J. P. Li and M. Ahmad, J. Power Sources, 2015, 273, 878-884.

44 J.-W. Wen, D.-W. Zhang, Y. Zang, X. Sun, B. Cheng, C.-X. Ding, Y. Yu and C.-H. Chen, Electrochim. Acta, 2014, 132, 193-199.

45 K. C. Klavetter, S. Garcia, N. Dahal, J. L. Snider, J. Pedro de Souza, T. H. Cell, M. A. Cassara, A. Heller, S. M. Humphrey and C. B. Mullins, J. Mater. Chem. A, 2014, 2, 14209-14221.

46 Q. Deng, L. Wang and J. Li, J. Mater. Sci., 2015, 50, 41424148.

47 H. Kim, J. Hong, Y.-U. Park, J. Kim, I. Hwang and K. Kang, Adv. Funct. Mater., 2015, 25, 534-541.

48 L. Ji, M. Gu, Y. Shao, X. Li, M. H. Engelhard, B. W. Arey, W. Wang, Z. Nie, J. Xiao, C. Wang, J.-G. Zhang and J. Liu, Adv. Mater., 2014, 26, 2901-2908.

49 M. M. Rahman, I. Sultana, Z. Chen, M. Srikanth, L. H. Li, X. J. Dai and Y. Chen, Nanoscale, 2015, 7, 13088-13095.

50 Z. Jian, P. Liu, F. Li, M. Chen and H. Zhou, J. Mater. Chem. A, 2014, 2, 13805-13809.

51 K. Tang, L. Fu, R. J. White, L. Yu, M.-M. Titirici, M. Antonietti and J. Maier, Adv. Energy Mater., 2012, 2, 873-877.

52 B. G. Choi, S.-J. Chang, Y. B. Lee, J. S. Bae, H. J. Kim and Y. S. Huh, Nanoscale, 2012, 4, 5924-5930.

53 X. Rui, W. Sun, C. Wu, Y. Yu and Q. Yan, Adv. Mater., 2015, 27, 6670-6676.

54 Y. Fang, L. Xiao, X. Ai, Y. Cao and H. Yang, Adv. Mater., 2015, 27, 5895-5900.

55 Z. Hu, Z. Zhu, F. Cheng, K. Zhang, J. Wang, C. Chen and J. Chen, Energy Environ. Sci., 2015, 8, 1309-1316.

56 J. Wang, J. Polleux, J. Lim and B. Dunn, J. Phys. Chem. C, 2007, 111, 14925-14931.

57 Z. Hu, L. Wang, K. Zhang, J. Wang, F. Cheng, Z. Tao and J. Chen, Angew. Chem., Int. Ed., 2014, 53, 12794-12798.

58 D. Larcher, G. Sudant, J. B. Leriche, Y. Chabre and J. M. Tarascon, J. Electrochem. Soc., 2002, 149, A234. 